\title{
Microstructure Evolution and Solidification Behavior of a Novel Semi-Solid Alloy Slurry Prepared by Vibrating Contraction Inclined Plate
}

\author{
Yan Liu ${ }^{1}$, Minqiang Gao ${ }^{2, *}$, Ying Fu ${ }^{2,3, *}$, Weirong Li ${ }^{4}$, Pan Yang ${ }^{4}$ and Renguo Guan ${ }^{1,2}$ \\ 1 Key Laboratory of Lightweight Structural Materials Liaoning Provence, \\ School of Materials Science and Engineering, Northeastern University, Shenyang 110819, China; \\ 1910146@stu.neu.edu.cn (Y.L.); guanrenguo@sina.cn (R.G.) \\ 2 Engineering Research Center of Continuous Extrusion, Ministry of Education, Dalian Jiaotong University, \\ Dalian 116028, China \\ 3 Songshan Lake Materials Laboratory, Dongguan 523808, China \\ 4 Dongguan Eontec Co., Ltd., Dongguan 523662, China; liwr@e-ande.com (W.L.); yangp@e-ande.com (P.Y.) \\ * Correspondence: mqgao@djtu.edu.cn (M.G.); fuying@sslab.org.cn (Y.F.)
}

Citation: Liu, Y.; Gao, M.; Fu, Y.;

Li, W.; Yang, P.; Guan, R.

Microstructure Evolution and

Solidification Behavior of a Novel Semi-Solid Alloy Slurry Prepared by Vibrating Contraction Inclined Plate. Metals 2021, 11, 1810. https:// doi.org/10.3390/met11111810

Academic Editor: Giulio Timelli

Received: 30 September 2021

Accepted: 8 November 2021

Published: 10 November 2021

Publisher's Note: MDPI stays neutral with regard to jurisdictional claims in published maps and institutional affiliations.

Copyright: (c) 2021 by the authors. Licensee MDPI, Basel, Switzerland. This article is an open access article distributed under the terms and conditions of the Creative Commons Attribution (CC BY) license (https:/ / creativecommons.org/licenses/by/ $4.0 /)$.

\begin{abstract}
In this work, based on the A356 alloy, a novel Al-Si-Mg-Cu-Fe-Sr alloy with good mechanical property and high thermal conductivity was developed. The semi-solid slurry of the alloy was prepared via the vibrating contraction inclined plate. The microstructure evolution and solidification behavior of the alloy were investigated. The results demonstrated that, compared with the A356 alloy, the enhanced property of the Al-Si-Mg-Cu-Fe-Sr alloy was associated with the size of primary $\alpha$-Al grains and morphology of eutectic Si phases. In addition, the preparation process parameters of semi-solid slurries, including the pouring temperature, inclination angle, and vibration frequency, had a crucial effect on the size and morphology of primary $\alpha$-Al grains. The optimized pouring temperature, inclination angle, and vibration frequency were $670{ }^{\circ} \mathrm{C}, 45^{\circ}$, and $60 \mathrm{~Hz}$, respectively. In this condition, for the primary $\alpha$-Al grains, a minimum grain diameter of $64.31 \mu \mathrm{m}$ and a maximum shape factor of 0.80 were obtained. This work provides a reference for the application of the alloy with high performance in the field of automobile and communication.
\end{abstract}

Keywords: semi-solid aluminum alloy; process parameter; solidification behavior; grain size; microstructure

\section{Introduction}

Semi-solid metal (SSM) processing technology, a modern and advanced technology, has an advantage of fabricating metal parts with complicated structure, high quality, and improved mechanical properties [1-3]. It is necessary to obtain the semi-solid slurry with spherical grains during SSM processing [4]. Some preparation methods of semi-solid slurries have been developed, such as mechanical stirring [5], electromagnetic stirring [6], gas induced semi-solid [7], and the indirect ultrasonic vibration method [8].

In order to develop the low-cost and simplified method, an inclined plate process for preparing the semi-solid slurry is proposed [9]. The melt is poured onto the inclined plate above the liquidus temperature and then the semi-solid slurry is formed when the melt flows through the inclined plate. For example, Taghavi et al. [10] studied the effect of the inclined plate length and angle on the thixotropic microstructure of the A356 alloy and found that the inclination angle of $40^{\circ}$ and length of inclined plate of $40 \mathrm{~cm}$ were optimized parameters to prepare the semi-solid slurry. Kund [11] pointed out that the microstructure of the A356 alloy was affected by the inclined plate length and cooling rate, i.e., when the plate length was $250 \mathrm{~mm}$, the desirable microstructure was obtained. Khosravi et al. [12] explored the optimization of the inclined plate process in the semi-solid A356 alloy; the result indicated that the pouring temperature of $660^{\circ} \mathrm{C}$, the cooling plate length of $360 \mathrm{~mm}$, 
and inclination angle of $48^{\circ}$ were the optimized parameters. It can be concluded that the process parameters of semi-solid slurries play a significant role in determining the microstructure, thus affecting the property of alloys.

These studies enhance our understanding of the preparation of semi-solid slurries. To avoid slurry adhesion on the plate surface and improve the slurry quality, we design a vibrating contraction inclined plate, including the cooling system, the vibrating system, and the tapered-runner design on the inclined plate. Compared with the common inclined plate process, the vibrating contraction inclined plate process has some advantages as follows. Firstly, the chilling effect is provided by the cooling water, which promotes the heterogeneous nucleation. Secondly, the shearing effect induced by the vibrating system inhibits the growth of dendrites and makes the primary $\alpha$-Al grains gradually evolve into spherical grains. Finally, the aim of the tapered-runner design is to change the heat and mass transfer via the contact between the melt and inner wall and further avoid the slurry adhesion on the plate surface.

The A356 alloy that is viewed as the most common aluminum alloy is used for SSM processing technology. With the development of automobile and communication, high requirements are put forward for the properties of alloys. Therefore, a novel alloy with a good combination of mechanical properties and thermal conductivity should be developed. Alloying has an important effect on the microstructure and mechanical property of aluminum alloys [13]. For example, the appropriate addition of $\mathrm{Mg}$ and $\mathrm{Cu}$ elements helps improve the mechanical property of aluminum alloys $[14,15]$. The Sr element has a unique advantage of varying the morphology of eutectic Si phases [16,17]. Appropriately increasing the Fe element enhances the demolding ability [18] and thermal stability [19].

Therefore, in this work, a novel Al-Si-Mg-Cu-Fe-Sr alloy was developed, and its semi-solid slurry was prepared via the vibrating contraction inclined plate. The enhanced property was analyzed by the microstructure observation. Furthermore, the effect of pouring temperature, inclination angle, and vibration frequency on the size and morphology of primary $\alpha$-Al grains was investigated. The microstructural evolution and solidification behavior of the alloy were analyzed.

\section{Materials and Methods}

An $\mathrm{Al}-8.2 \mathrm{Si}-0.46 \mathrm{Mg}-0.53 \mathrm{Fe}-0.15 \mathrm{Cu}-0.01 \mathrm{Sr}(\mathrm{wt} \%$ ) alloy, termed the $\mathrm{Al}-\mathrm{Si}-\mathrm{Mg}-\mathrm{Cu}-\mathrm{Fe}-$ $\mathrm{Sr}$ alloy, was used as the experimental material. The $\mathrm{Al}-\mathrm{Si}-\mathrm{Mg}-\mathrm{Cu}-\mathrm{Fe}-\mathrm{Sr}$ alloy was melted at $750{ }^{\circ} \mathrm{C}$ in a graphite clay crucible using a resistance furnace. After the melt was completely melted, degassing and deslagging were carried out at $720{ }^{\circ} \mathrm{C}$ and then held for $30 \mathrm{~min}$. The melt temperature was reduced to $700{ }^{\circ} \mathrm{C}$ and then casted into a mold $(\varnothing 45 \mathrm{~mm} \times 350 \mathrm{~mm}$ ) to form cylindrical ingots. For comparison, the A356 alloy (Al-7.3Si-0.41Mg-0.15Fe ( $\mathrm{wt} \%)$ ) was prepared by the same casting process.

The effect of various parameters on the microstructure of the semi-solid alloy was investigated using the vibrating contraction inclined plate process, as shown in Figure 1a. The process parameters, such as pouring temperature, inclination angle, and vibration frequency, were listed in Table 1 . The alloy was melted at $750{ }^{\circ} \mathrm{C}$. When the melt was completely melted, degassing and deslagging were carried out at $720^{\circ} \mathrm{C}$ and then held for $30 \mathrm{~min}$. After cooling to the target temperature, the melt was poured into a tundish. The function of the tundish was to ensure that the melt was steadily introduced into the taperedrunner of the inclined plate coated by a thin layer of $\mathrm{TiO}_{2}$, and the melt entered a mold with a preheated temperature of $200{ }^{\circ} \mathrm{C}$, as shown in Figure $1 \mathrm{~b}$. The size of the tapered-runner was shown in Figure 1c. The melt and mold were cooled down to room temperature. 


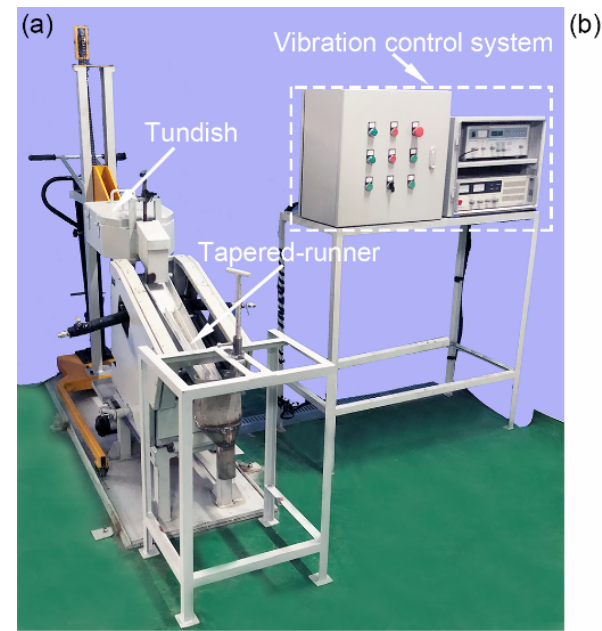

(b)

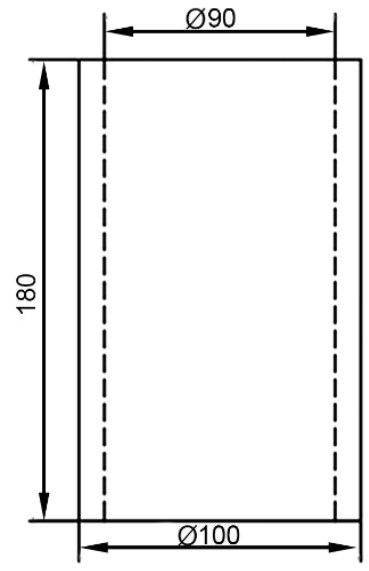

(c)

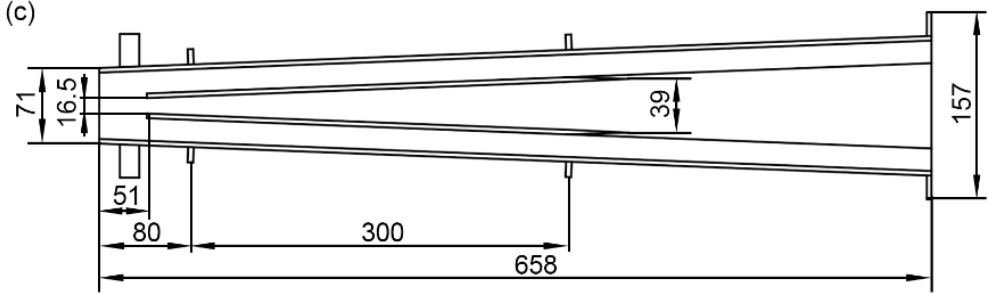

Figure 1. (a) Vibrating contraction inclined plate setup; the size of (b) the mold and (c) tapered-runner (unit: $\mathrm{mm}$ ).

Table 1. Various parameters of the vibrating contraction inclined plate.

\begin{tabular}{ccc}
\hline Pouring Temperature $\left({ }^{\circ} \mathbf{C}\right)$ & Inclination Angle $\left(^{\circ}\right)$ & Vibration Frequency $\mathbf{~} \mathbf{H z})$ \\
\hline 660 & 45 & 0 \\
670 & 45 & 0 \\
680 & 45 & 0 \\
690 & 45 & 0 \\
700 & 45 & 0 \\
670 & 15 & 0 \\
670 & 30 & 0 \\
670 & 60 & 0 \\
670 & 45 & 30 \\
670 & 45 & 60 \\
670 & 45 & 90 \\
\hline
\end{tabular}

Specimens for optical metallography observation were ground, mechanically polished, and then etched using a Keller's agent for $10 \mathrm{~s}$. Microstructure was observed using an optical microscopy (OM, OLYMPUS-DSX-500, Tokyo, Japan). The Image-Pro Plus analysis software was used to analyze the average grain diameter and shape factor of primary $\alpha$-Al grains, which could be calculated by [1]

$$
\begin{gathered}
D=\sum_{i=1}^{N} \sqrt{4 A / \pi} / N, \\
F_{\mathrm{S}}=N / \sum_{i=1}^{N}\left[C^{2} /(4 \pi A)\right],
\end{gathered}
$$

where $D, F_{\mathrm{S}}, A, N$, and $C$ were the average diameter, shape factor, area, number, and perimeter of the primary $\alpha-\mathrm{Al}$ grains, respectively. The secondary phases in the alloy were observed by a scanning electron microscope (SEM, Zeiss Supra 55, Jena, Germany) equipped with the energy dispersive spectroscopy (EDS). 
Tensile tests were carried out at a tensile rate of $2 \mathrm{~mm} / \mathrm{min}$ using a universal tensile machine (UTM, Instron5582, Norwood, MA, USA). Each specimen was measured at least three times, and the average value was calculated. The specimens were processed into cylinders $(\varnothing 12.7 \mathrm{~mm} \times 3 \mathrm{~mm})$ to measure the thermal diffusivity using the laser flash diffusivity instrument (FLD, NETZSCH LFA 427, Jena, Germany). The specimen density was determined using Archimedes method. In addition, the specific heat was measured with a differential scanning calorimeter (DSC, Setaram DSC131, Caluire-et-Cuire, France). Therefore, the thermal conductivity was calculated by [16]

$$
\lambda=\alpha \rho c_{\mathrm{p}}
$$

where $\lambda, \alpha, \rho$, and $c_{\mathrm{p}}$ were the thermal conductivity, thermal diffusivity, density, and specific heat, respectively.

\section{Results}

\subsection{Microstructure}

Figure 2 shows microstructure of the A356 and Al-Si-Mg-Cu-Fe-Sr alloys. Coarse dendrites are observed in the A356 alloy, as shown in Figure 2a. Compared with the A356 alloy, the Al-Si-Mg-Cu-Fe-Sr alloy displays a finer dendrite structure, as shown in Figure $2 b$. In addition, secondary phases also are observed in Figure 2.
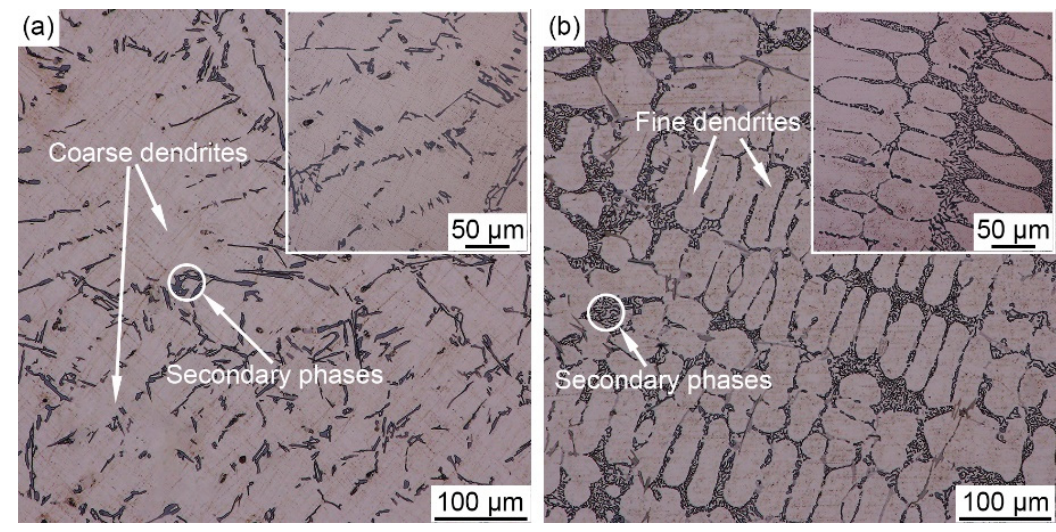

Figure 2. OM images showing the $\alpha$-Al grains: (a) A356 alloy; (b) $\mathrm{Al}-\mathrm{Si}-\mathrm{Mg}-\mathrm{Cu}-\mathrm{Fe}-\mathrm{Sr}$ alloy.

Secondary phases of the A356 and Al-Si-Mg-Cu-Fe-Sr alloys are further observed by SEM, as shown in Figure 3. The EDS result for Point A in Figure 3a shows that the needle phase mainly consists of $\mathrm{Al}$ and $\mathrm{Si}$ elements, as shown in Figure 3c. The EDS point for Point B shows that the needle phase contains mainly $\mathrm{Al}, \mathrm{Fe}$, and Si elements, as shown in Figure 3e. According to the literature, the Point A and Point B are the eutectic Si phase and $\beta$-AlFeSi phase, respectively [20]. The SEM micrograph of secondary phases in the Al-Si-Mg-Cu-Fe-Sr alloy is shown in Figure 3b. The EDS point scanning result for Point $\mathrm{C}$ is shown in Figure $3 \mathrm{~d}$; this result shows that the fibrous phase mainly consists of $\mathrm{Al}$ and Si elements. The EDS result for Point D shows that the needle phase contains mainly Al and Fe elements, as shown in Figure 3f. The result indicates that the Point C and Point D present a eutectic Si phase and iron-rich intermetallics, respectively.

In addition, element distributions of $\mathrm{Al}-\mathrm{Si}-\mathrm{Mg}-\mathrm{Cu}-\mathrm{Fe}-\mathrm{Sr}$ alloy are determined, as shown in Figure 4. It is found that $\mathrm{Al}, \mathrm{Si}$, and Fe elements form the iron-rich intermetallics, and $\mathrm{Mg}, \mathrm{Cu}$, and $\mathrm{Sr}$ elements are almost dissolved in the matrix, as shown in Figure $4 \mathrm{~b}-\mathrm{g}$. Meanwhile, the iron-rich intermetallics mainly consist of $\mathrm{Al}, \mathrm{Si}$, and Fe elements. Based on the previous work, the iron-rich phase is determined to be the $\beta$-AlFeSi phase [14]. 

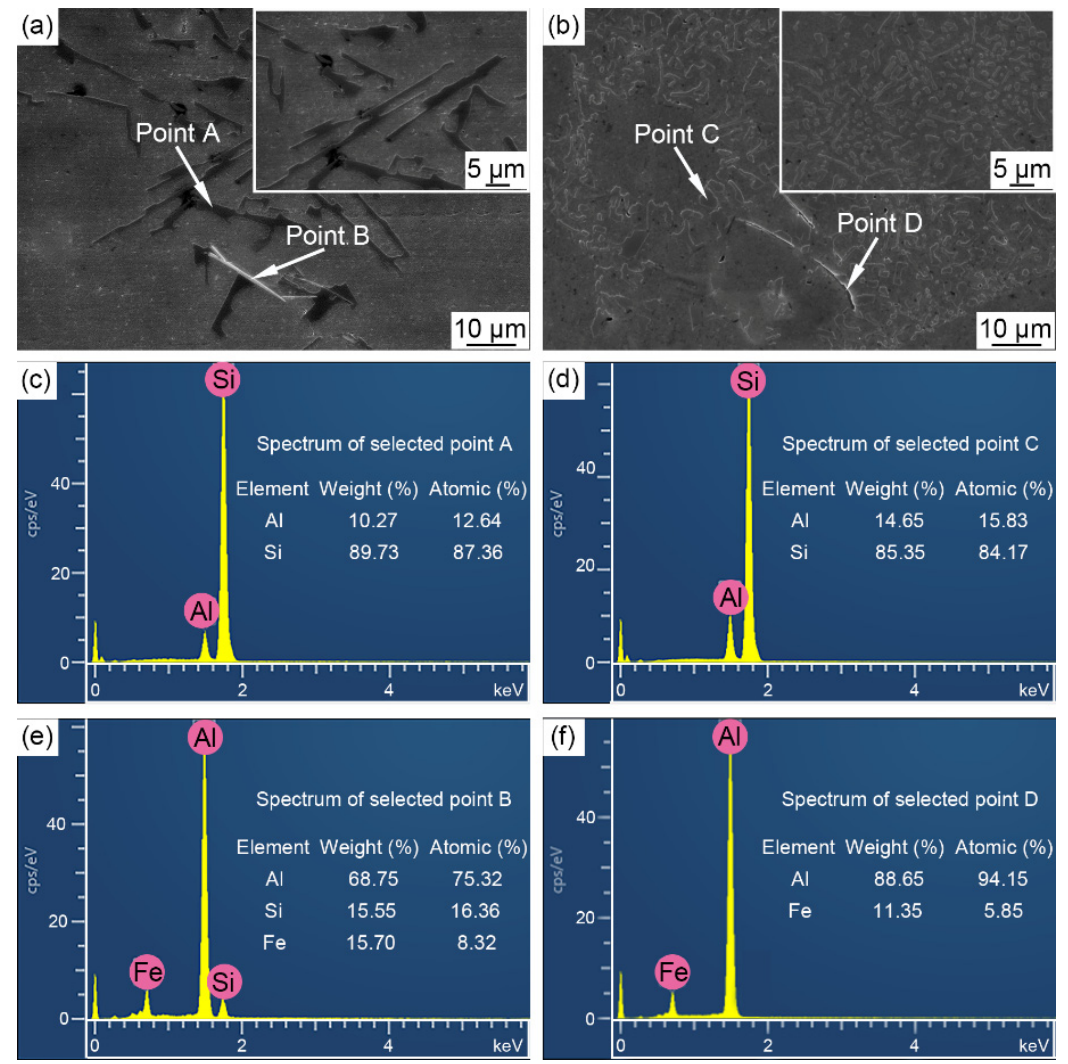

Figure 3. SEM micrographs of secondary phases in (a) A356 alloy and (b) Al-Si-Mg-Cu-Fe-Sr alloy. $(\mathbf{c}, \mathbf{e})$ are the corresponding EDS results of the eutectic Si phase and $\beta$-AlFeSi phase in (a), respectively. $(\mathbf{d}, \mathbf{f})$ are the corresponding EDS results of the eutectic Si phase and iron-rich intermetallics in (b), respectively.
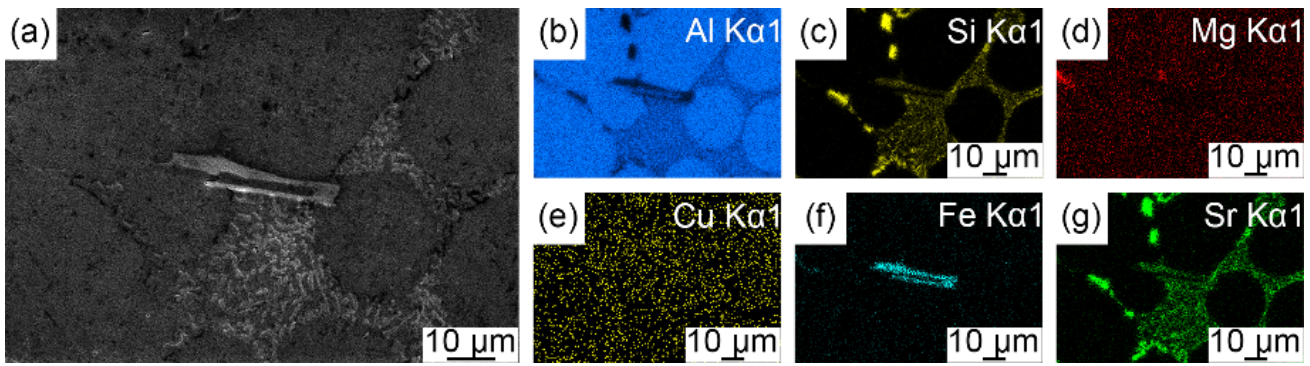

Figure 4. SEM micrograph and the corresponding element distribution: (a) SEM image of the Al-Si-Mg$\mathrm{Cu}-\mathrm{Fe}-\mathrm{Sr}$ alloy; (b-g) presenting the distribution of $\mathrm{Al}, \mathrm{Si}, \mathrm{Mg}, \mathrm{Cu}, \mathrm{Fe}$, and $\mathrm{Sr}$ elements in (a), respectively.

\subsection{Mechanical Property and Thermal Conductivity}

Figure 5a shows stress-strain curves of the A356 and Al-Si-Mg-Cu-Fe-Sr alloys. The tensile properties of the $\mathrm{Al}-\mathrm{Si}-\mathrm{Mg}-\mathrm{Cu}-\mathrm{Fe}-\mathrm{Sr}$ alloy, including the ultimate tensile strength (UTS), yield strength (YS), and elongation (EL), are higher than those of the A356 alloy. The mechanical properties of two alloys are listed in Table 2. The UTS, YS, and EL of the $\mathrm{Al}-\mathrm{Si}-\mathrm{Mg}-\mathrm{Cu}-\mathrm{Fe}-\mathrm{Sr}$ alloy are $192.2 \mathrm{MPa}, 117.3 \mathrm{MPa}$, and $3.8 \%$, respectively, which increase by $28 \%, 48 \%$, and $3 \%$ in contrast to the A356 alloy. 

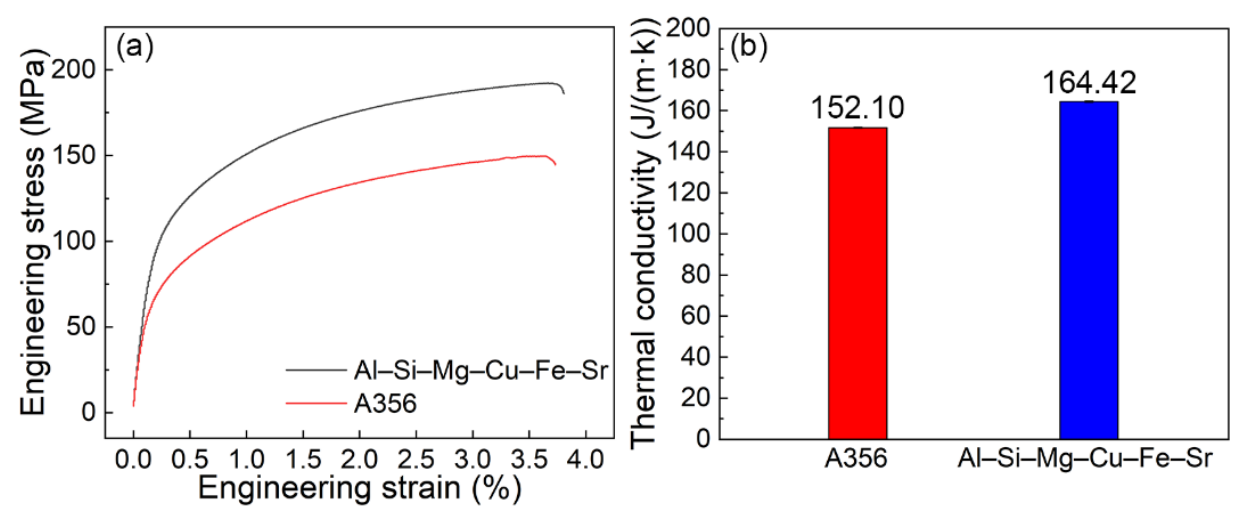

Figure 5. (a) Mechanical property and (b) thermal conductivity of the A356 and Al-Si-Mg-Cu-FeSr alloys.

Table 2. Tensile property of the A356 and Al-Si-Mg-Cu-Fe-Sr alloys.

\begin{tabular}{cccc}
\hline \multirow{2}{*}{ Alloy } & \multicolumn{3}{c}{ Mechanical Property } \\
\cline { 2 - 4 } & UTS (MPa) & YS (MPa) & EL (\%) \\
\hline A356 & $150.1 \pm 0.5$ & $79.3 \pm 0.9$ & $3.7 \pm 0.3$ \\
Al-Si-Mg-Cu-Fe-Sr & $192.2 \pm 3.2$ & $117.3 \pm 1.4$ & $3.8 \pm 0.2$ \\
\hline
\end{tabular}

Figure $5 \mathrm{~b}$ displays the thermal conductivity of the A356 and Al-Si-Mg-Cu-Fe-Sr alloys. The Al-Si-Mg-Cu-Fe-Sr alloy possesses a higher thermal conductivity compared with the A356 alloy. The thermal diffusivity, density, and specific heat of two alloys are summarized in Table 3. The thermal conductivity of the Al-Si-Mg-Cu-Fe-Sr alloy is calculated by Formula (3) to be $164.42 \mathrm{~W} /(\mathrm{m} \cdot \mathrm{K})$, which is $8 \%$ larger than that of the A356 alloy.

Table 3. Thermal conductivity of the A356 and Al-Si-Mg-Cu-Fe-Sr alloys.

\begin{tabular}{ccccc}
\hline Alloy & $\begin{array}{c}\text { Thermal Diffusivity, } \boldsymbol{\alpha} \\
\left(\mathbf{m m}^{\mathbf{2}} / \mathbf{s}\right)\end{array}$ & Density, $\boldsymbol{\rho}\left(\mathbf{g} / \mathbf{c m}^{\mathbf{3}}\right)$ & $\begin{array}{c}\text { Specific Heat, } c_{\mathbf{p}} \\
(\mathbf{W} / \mathbf{( g} \cdot \mathbf{K}))\end{array}$ & $\begin{array}{c}\text { Thermal Diffusivity, } \lambda \\
(\mathbf{W} /(\mathbf{m} \cdot \mathbf{K}))\end{array}$ \\
\hline A356 & $58.60 \pm 0.12$ & $2.52 \pm 0.03$ & $1.03 \pm 0.02$ & $152.10 \pm 0.26$ \\
$\mathrm{Al}-\mathrm{Si}-\mathrm{Mg}-\mathrm{Cu}-\mathrm{Fe}-\mathrm{Sr}$ & $59.66 \pm 0.13$ & $2.65 \pm 0.02$ & $1.04 \pm 0.01$ & $164.42 \pm 0.30$ \\
\hline
\end{tabular}

\subsection{Microstructure Evolution in the Semi-Solid Al-Si-Mg-Cu-Fe-Sr Alloy \\ 3.3.1. Effect of Pouring Temperature}

Figure 6 shows the microstructure of the $\mathrm{Al}-\mathrm{Si}-\mathrm{Mg}-\mathrm{Cu}-\mathrm{Fe}-\mathrm{Sr}$ alloy prepared by the vibrating contraction inclined plate with an inclination angle of $45^{\circ}$ and vibration frequency of $0 \mathrm{~Hz}$ under different pouring temperatures. When the pouring temperature is $660^{\circ} \mathrm{C}$, coarse dendrites are observed, as shown in Figure 6a, and the blocked slurry ratio increases on the vibrating contraction inclined plate. The grain diameter and shape factor of primary $\alpha$-Al grains are $76.78 \mu \mathrm{m}$ and 0.63 , respectively. As the pouring temperature increases to $670{ }^{\circ} \mathrm{C}$, few dendrites are almost found, and the primary $\alpha$-Al grains display a spherical/near spherical shape, as shown in Figure $6 \mathrm{~b}$. The primary $\alpha$-Al grains diameter reduces to $69.56 \mu \mathrm{m}$, and the shape factor increases to 0.71 . When the pouring temperature increases to $680^{\circ} \mathrm{C}$, the primary $\alpha$ - $\mathrm{Al}$ grains mainly consist of a few of the dendrites and spherical/near spherical grains, as shown in Figure 6c. The grain diameter and shape factor of primary $\alpha$-Al grains are $74.43 \mu \mathrm{m}$ and 0.68 , respectively. As the pouring temperature further increases to $690^{\circ} \mathrm{C}$, the number of dendrites increases significantly; however, the number of near spherical grains decreases, as shown in Figure 6d. The average diameter of primary $\alpha$-Al grains increases to $78.15 \mu \mathrm{m}$, and the shape factor decreases to 0.65 . When the pouring temperature is $700^{\circ} \mathrm{C}$, some dendrites and a few rose-like grains are observed, 
as shown in Figure 6e. The grain diameter and shape factor of primary $\alpha$-Al grains are $88.65 \mu \mathrm{m}$ and 0.63 , respectively. Therefore, when the pouring temperature increases from 660 to $700{ }^{\circ} \mathrm{C}$, the grain diameter firstly decreases and then increases, and the shape factor displays an opposite variation trend, as shown in Figure 7. Therefore, the optimized pouring temperature is confirmed to be $670{ }^{\circ} \mathrm{C}$.
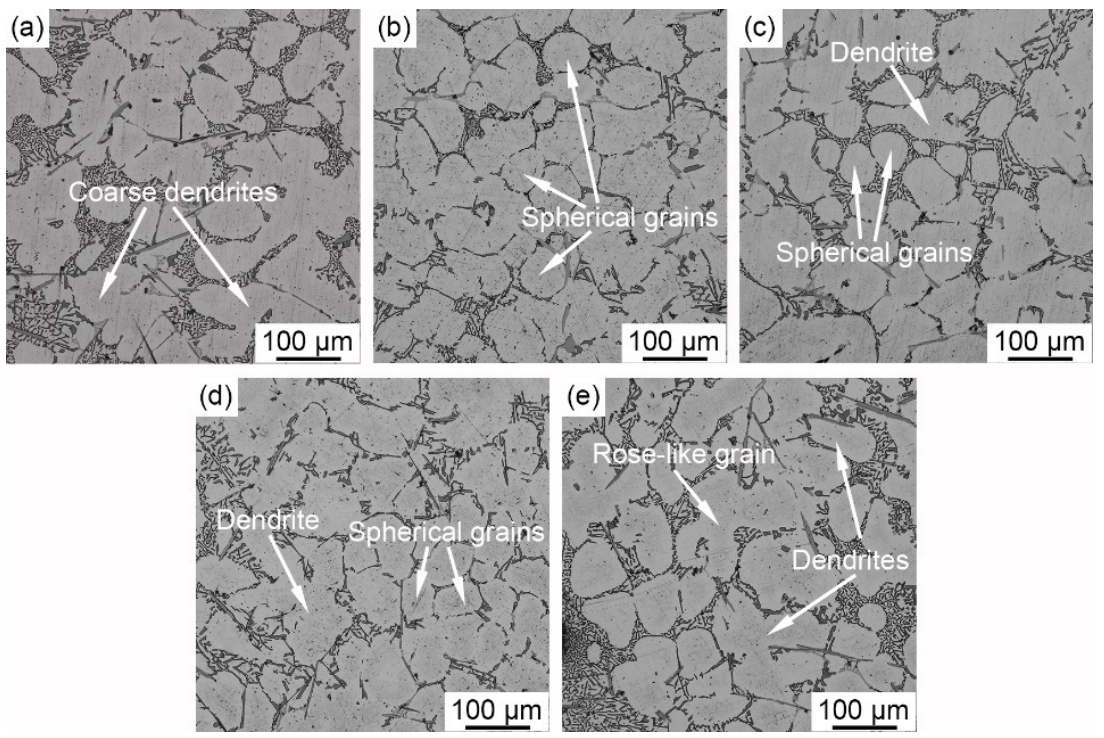

Figure 6. OM images showing the morphology of primary $\alpha$ - $\mathrm{Al}$ grains in the $\mathrm{Al}-\mathrm{Si}-\mathrm{Mg}-\mathrm{Cu}-\mathrm{Fe}-\mathrm{Sr}$ alloy prepared at different pouring temperatures: (a) $660{ }^{\circ} \mathrm{C}$; (b) $670{ }^{\circ} \mathrm{C}$; (c) $680{ }^{\circ} \mathrm{C}$; (d) $690^{\circ} \mathrm{C}$; (e) $700{ }^{\circ} \mathrm{C}$.

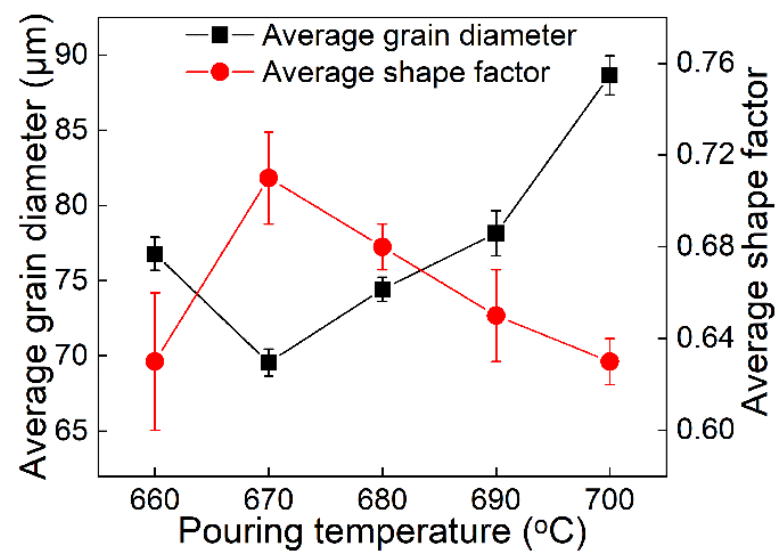

Figure 7. Average grain diameter and average shape factor as functions of pouring temperature. The inclination angle and vibration frequency are $45^{\circ}$ and $0 \mathrm{~Hz}$, respectively.

\subsubsection{Effect of Inclination Angle}

Figure 8 shows the microstructure of $\mathrm{Al}-\mathrm{Si}-\mathrm{Mg}-\mathrm{Cu}-\mathrm{Fe}-\mathrm{Sr}$ alloy prepared at a pouring temperature $670^{\circ} \mathrm{C}$ and vibration frequency of $0 \mathrm{~Hz}$ under various inclination angles. When the inclination angle is $15^{\circ}$, some dendrites are observed, as shown in Figure 8a. The grain diameter and shape factor of primary $\alpha$-Al grains are $82.73 \mu \mathrm{m}$ and 0.64 , respectively. When the inclination angle increases from $15^{\circ}$ to $30^{\circ}$, a number of the dendrites decreases and spherical/near spherical grains increases, as shown in Figure $8 \mathrm{~b}$. The grain diameter and shape factor are $81.36 \mu \mathrm{m}$ and 0.66 , respectively. As the inclination angle increases to $45^{\circ}$, the primary $\alpha-\mathrm{Al}$ grains mainly consist of spherical/near spherical grains, as shown in Figure $8 \mathrm{c}$. The grain diameter and the shape factor are $69.56 \mu \mathrm{m}$ and 0.71 , respectively. However, when the inclination angle is $60^{\circ}$, a few dendrites are observed, as shown in 
Figure $8 \mathrm{~d}$. The grain diameter and shape factor of the primary $\alpha$-Al grains were $72.25 \mu \mathrm{m}$ and 0.56 , respectively. Therefore, when the inclination angle increases from $15^{\circ}$ to $60^{\circ}$, the grain diameter firstly decreases and then increases, and the shape factor firstly increases and then decreases, as shown in Figure 9. It is found that the inclination angle of $45^{\circ}$ is an optimized processing parameter.
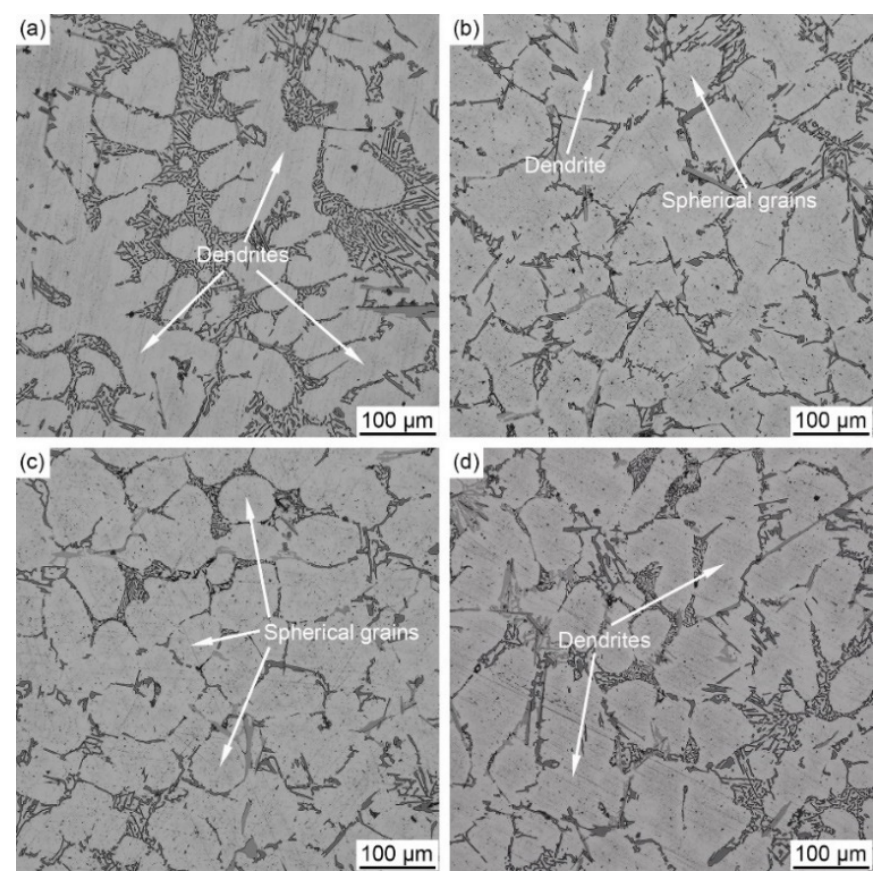

Figure 8. OM images displaying the morphology of primary $\alpha-\mathrm{Al}$ grains in the $\mathrm{Al}-\mathrm{Si}-\mathrm{Mg}-\mathrm{Cu}-\mathrm{Fe}-\mathrm{Sr}$ alloy prepared at different inclination angles: (a) $15^{\circ}$; (b) $30^{\circ}$; (c) $45^{\circ}$; (d) $60^{\circ}$.

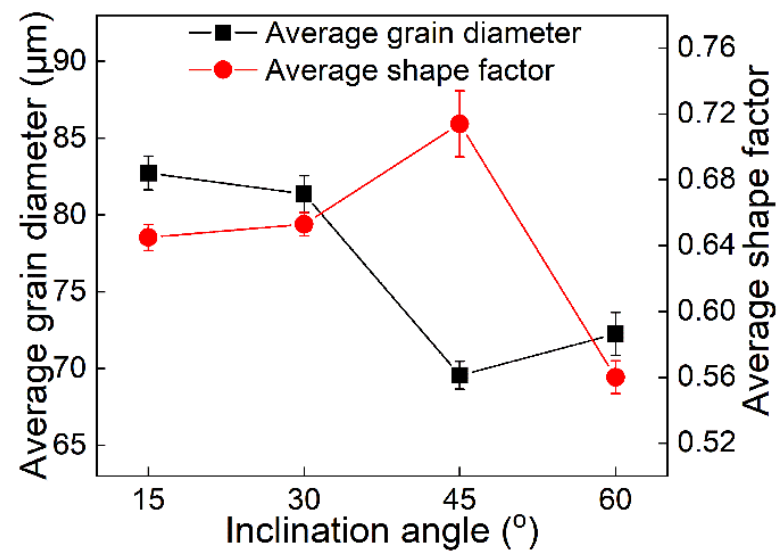

Figure 9. Average grain diameter and average shape factor as functions of inclination angle. The pouring temperature and vibration frequency are $670{ }^{\circ} \mathrm{C}$ and $0 \mathrm{~Hz}$, respectively.

\subsubsection{Effect of Vibration Frequency}

Figure 10 shows microstructure of $\mathrm{Al}-\mathrm{Si}-\mathrm{Mg}-\mathrm{Cu}-\mathrm{Fe}-\mathrm{Sr}$ alloy with a pouring temperature of $670{ }^{\circ} \mathrm{C}$ and inclination angle of $45^{\circ}$ under different vibration frequencies. When the vibration frequency is $0 \mathrm{~Hz}$, few dendrites almost are found, and the primary $\alpha$-Al grains display a spherical/near spherical shape, as shown in Figure 10a. The grain diameter and shape factor are $69.56 \mu \mathrm{m}$ and 0.71 , respectively. With the vibration frequency increases from 30 to $60 \mathrm{~Hz}$, the primary $\alpha$-Al grains mainly consist of spherical/near spherical grains, as shown in Figure 10b,c; the grain diameter decreases from 66.99 to $64.31 \mu \mathrm{m}$, and the shape factor increases from 0.77 to 0.80 . However, when the vibration frequency increases 
to $90 \mathrm{~Hz}$, the number of the spherical/near spherical grains decreases, and the number of the dendrites increases, as shown in Figure 10d. The grain diameter and shape factor are $72.19 \mu \mathrm{m}$ and 0.72 , respectively. Therefore, when the vibration frequency increases from 0 to $90 \mathrm{~Hz}$, the grain diameter firstly decreases and then increases, and the shape factor firstly increases and then decreases, as shown in Figure 11. The primary $\alpha$-Al grains having the minimum grain size and maximum shape factor are obtained at a vibration frequency of $60 \mathrm{~Hz}$.
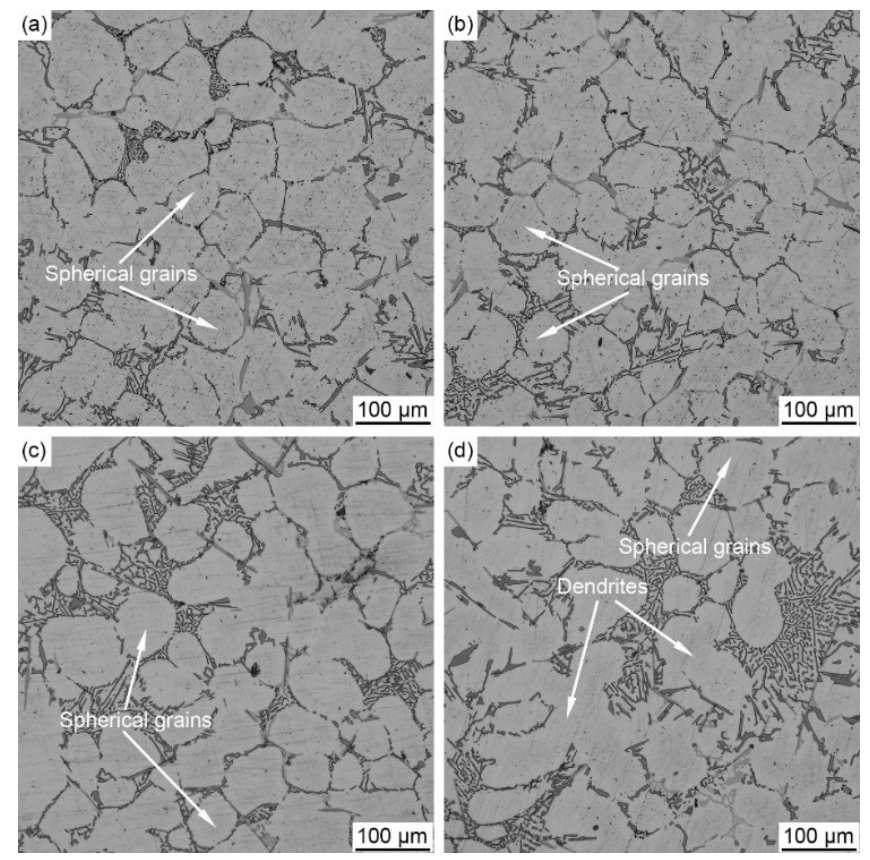

Figure 10. OM images displaying the morphology of primary $\alpha$-Al grains in the $\mathrm{Al}-\mathrm{Si}-\mathrm{Mg}-\mathrm{Cu}-\mathrm{Fe}-\mathrm{Sr}$ alloy prepared at different vibration frequencies: (a) $0 \mathrm{~Hz}$; (b) $30 \mathrm{~Hz}$; (c) $60 \mathrm{~Hz}$; (d) $90 \mathrm{~Hz}$.

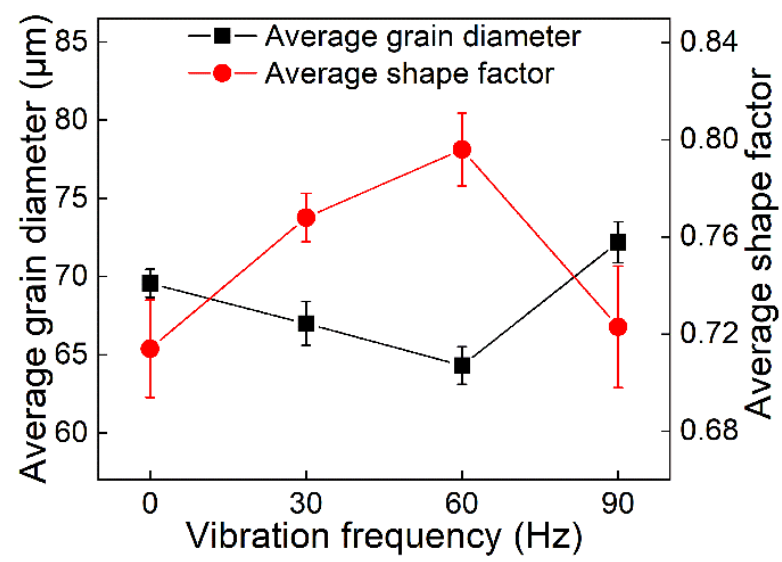

Figure 11. Average grain diameter and average shape factor as functions of vibration frequency. The!pouring temperature and inclination angle are $670^{\circ} \mathrm{C}$ and $45^{\circ}$, respectively.

\section{Discussion}

\subsection{Microstructure Evolution and Improved Property}

Compared with the A356 alloy, the $\mathrm{Al}-\mathrm{Si}-\mathrm{Mg}-\mathrm{Cu}-\mathrm{Fe}-\mathrm{Sr}$ alloy displays a finer dendrite structure. This is because the $\mathrm{Sr}$ element can decrease the eutectic reaction temperature of the cast Al-Si alloy, which increases the solidification temperature range and number of dendrites [21,22]. Therefore, the more dendrites, the finer the primary $\alpha$-Al grains in the certain area. In addition, the Sr element, as a surface-active element, can cause a component 
supercooling effect through surface adsorption, thus preventing the growth of eutectic $\mathrm{Si}$ phases with a needle shape [23]. The eutectic Si phases grow by the twin plane reentrant edge (TPRE) mechanism, resulting in a change in morphology of eutectic Si phases, i.e., from the coarse needle shape to a finely fibrous shape [24].

The Al-Si-Mg-Cu-Fe-Sr alloy has better mechanical properties than the A356 alloy. On the one hand, the YS $\left(\sigma_{\mathrm{ys}}\right)$ is relevant to the size of primary $\alpha$-Al grains, which follows the Hall-Petch relationship [25]:

$$
\sigma_{\mathrm{ys}}=\sigma_{0}+K_{\mathrm{y}} d^{-1 / 2},
$$

where $\sigma_{0}$ is the single crystal yield strength, $K_{\mathrm{y}}$ is the strengthening co-efficient, and $d$ is the size of the primary $\alpha$-Al grains. Therefore, it is expected that a decrease in size of primary $\alpha$-Al grains will cause an increase in strength. Compared with the A356 alloy, the $\mathrm{Al}-\mathrm{Si}-\mathrm{Mg}-\mathrm{Cu}-\mathrm{Fe}-\mathrm{Sr}$ alloy has finer primary $\alpha$-Al grains, leading to improved mechanical properties. On the other hand, the morphology of eutectic Si phases plays an important role in the mechanical behavior of Al-Si alloys [26,27]. In the A356 alloy, eutectic Si phases possess a coarse needle shape, which accelerates the crack propagation rate and decreases the mechanical property [28]. However, in the $\mathrm{Al}-\mathrm{Si}-\mathrm{Mg}-\mathrm{Cu}-\mathrm{Fe}-\mathrm{Sr}$ alloy, eutectic $\mathrm{Si}$ phases with a short fibrous shape due to the addition of Sr element are obtained, which helps the improvement in mechanical property [29].

In addition to mechanical property, the $\mathrm{Al}-\mathrm{Si}-\mathrm{Mg}-\mathrm{Cu}-\mathrm{Fe}-\mathrm{Sr}$ alloy has a higher thermal conductivity in comparison with the A356 alloy. This is closely associated with the morphology of eutectic Si phases [16,30]. In the A356 alloy, the formation of needle-shaped eutectic $\mathrm{Si}$ phases results in the decrease in mean free path and increase in electron scattering [30]. On the contrary, in the $\mathrm{Al}-\mathrm{Si}-\mathrm{Mg}-\mathrm{Cu}-\mathrm{Fe}-\mathrm{Sr}$ alloy, eutectic Si phases with a short fibrous shape play an important role in increasing the electron channel, thereby decreasing the electron scattering and increasing the mean free path [16]. Therefore, the acquisition of fibrous eutectic Si phases is beneficial for the increase in thermal conductivity.

\subsection{Solidification Behavior}

\subsubsection{Effect of Pouring Temperature on Primary $\alpha$-Al Grains}

With the increase in pouring temperature from 670 to $700{ }^{\circ} \mathrm{C}$, there is an increase in grain diameter and a decrease in shape factor. The chilling effect is provided by the cooling water tank, resulting in the formation of crystal nuclei on the inclined plate. These crystal nuclei are detached from the inclined plate and are collected in the mold. The low pouring temperature results in a large sub-cooling degree and nucleation ratio [31]. On the other hand, the low pouring temperature causes the primary $\alpha$-Al nucleus to not be remelted, thus increasing the effective nucleation ratio [31]. Therefore, the low pouring temperature makes the primary $\alpha$-Al grains grow into the spherical shape and possess a small size [32]. However, when the pouring temperature further decreases to $660^{\circ} \mathrm{C}$, due to the deterioration of melt fluidity, some primary $\alpha-\mathrm{Al}$ nuclei grow up and firmly attach on the inclined plate instead of being brought into the melt, resulting in an increase in blocked slurry ratio [33], thereby increasing the grain size. In addition, the obvious adhesion phenomenon emerges at the pouring temperature of $660^{\circ} \mathrm{C}$. It is not easy to solve the blockage problem by changing the vibration frequency and/or inclination angle. Therefore, the pouring temperature has a great influence on the adhesion phenomenon.

\subsubsection{Effect of Inclination Angle on Primary $\alpha$-Al Grains}

When the inclination angle is $45^{\circ}$, the desirable primary $\alpha$-Al grains are acquired. The gravity acceleration component of the melt along the inclined plate is determined by the inclination angle. This affects the flowing speed of the melt and the shearing effect. The shearing force along the inclined plate $(\tau)$ as a function of the inclination angle $(\alpha)$ is expressed as:

$$
\tau=\eta \frac{\sqrt{2 \cdot g \sin \alpha \cdot L}}{h}
$$


where $\eta$ is the viscosity of the alloy; $g$ is the gravity acceleration; $L$ is the distance originated from the flow starting point of the inclined plate; $h$ is the vertical distance from the inclined plate surface. Therefore, when the inclination angle is $15^{\circ}$, the velocity of flow is slow and the shearing effect is small, which is detrimental to the breaking of dendrites [12]. As the inclination angle increases, the shearing effect increases, and the primary $\alpha$-Al grains tend to grow into the spherical shape. However, when the inclination angle further increases to $60^{\circ}$, the flowing velocity increases, while the shearing time decreases, which decreases the shearing effect. Therefore, the morphology of primary $\alpha-\mathrm{Al}$ grains varies again.

\subsubsection{Effect of Vibration Frequency on Primary $\alpha$-Al Grains}

When the vibration frequency increases from 0 to $90 \mathrm{~Hz}$, the grain diameter decreases initially and increases afterwards. The vibration frequency will affect the vibration amplitude. The contact time between the inclined plate and melt and the shearing effect are controlled by vibration amplitude [34]. When the vibration frequency is small, the vibration period and amplitude of the inclined plate are large, while the contact between the melt and inclined plate is poor, which decreases the shearing effect on breaking the dendrites [34]. The small vibration frequency results in the short contact time, which decreases the heat-exchange between the melt and inclined plate and increases the grain size. In addition, the short contact time can also cause an inhomogeneous cooling of the melt, resulting in a change in grain size. As the vibration frequency increases, mutual movement between the primary $\alpha$-Al grains and unsolidified liquid phases in the semi-solid slurry is enhanced, resulting in a viscous shear in the semi-solid slurry [35]. Under the shearing effect, most primary $\alpha$-Al grains are broken into new grains or nucleation cores, which helps to decrease the size of primary $\alpha-\mathrm{Al}$ grains. However, when the vibration frequency increases to $90 \mathrm{~Hz}$, the vibration period and amplitude are decreased, and the effect of vibration on the breaking of dendrites is not obvious.

\section{Conclusions}

A novel Al-Si-Mg-Cu-Fe-Sr alloy with good performance was developed. The process parameters of the semi-solid slurry prepared by the vibrating contraction inclined plate were optimized. The solidification behavior of the semi-solid alloy was discussed. The main conclusions were summarized as follows:

(1) Compared with the A356 alloy, the Al-Si-Mg-Cu-Fe-Sr alloy had a better combination of mechanical property and thermal conductivity, which was related to the size of primary $\alpha$-Al grains and morphology of eutectic Si phases.

(2) The process parameters had an important effect on the solidification behavior of primary $\alpha-\mathrm{Al}$ grains in the semi-solid $\mathrm{Al}-\mathrm{Si}-\mathrm{Mg}-\mathrm{Cu}-\mathrm{Fe}-\mathrm{Sr}$ alloy prepared by the vibrating contraction inclined plate. Compared with the vibration frequency, the pouring temperature or inclination angle may be dominant during preparing the semisolid slurry.

(3) When the pouring temperature, inclination angle, and vibration frequency are $670{ }^{\circ} \mathrm{C}$, $45^{\circ}$, and $60 \mathrm{~Hz}$, desirable primary $\alpha$-Al grains with a grain diameter of $64.31 \mu \mathrm{m}$ and a shape factor of 0.80 in the $\mathrm{Al}-\mathrm{Si}-\mathrm{Mg}-\mathrm{Cu}-\mathrm{Fe}-\mathrm{Sr}$ alloy were obtained.

Author Contributions: Conceptualization, Y.L. and M.G.; methodology, Y.L. and M.G.; software, Y.L.; validation, Y.L., M.G. and Y.F.; formal analysis, Y.L. and M.G.; investigation, Y.L., W.L. and P.Y.; data curation, Y.L. and M.G.; writing—original draft preparation, Y.L.; writing—review and editing, Y.L. and M.G.; supervision, R.G.; project administration, R.G.; funding acquisition, R.G. All authors have read and agreed to the published version of the manuscript.

Funding: This research was funded by National Key Research and Development Program of China [grant No. 2018YFB2001800], National Natural Science Foundation of China [grant No. 51871184], and LiaoNing Revitalization Talents Program [No. XLYC1802128].

Institutional Review Board Statement: Not applicable. 
Informed Consent Statement: Not applicable.

Data Availability Statement: Data presented in this article are available at request from the corresponding author.

Acknowledgments: We would like to thank Zhiping Guan and Jinguo Wang for their help in the composition design of the alloy.

Conflicts of Interest: The authors declare no conflict of interest.

\section{References}

1. Taghavi, F.; Saghafian, H.; Kharrazi, Y.H.K. Study on the ability of mechanical vibration for the production of thixotropic microstructure in A356 aluminum alloy. Mater. Des. 2009, 30, 115-121. [CrossRef]

2. Wallace, G.; Jackson, A.P.; Midson, S.P.; Zhu, Q. High-quality aluminum turbocharger impellers produced by thixocasting. Trans. Nonferrous Met. Soc. China 2010, 20, 1786-1791. [CrossRef]

3. Guan, R.G.; Zhao, Z.Y.; Li, Y.D.; Chen, T.J.; Xu, S.X.; Qi, P.X. Microstructure and properties of squeeze cast A356 alloy processed with a vibrating slope. J. Mater. Process. Technol. 2016, 229, 514-519. [CrossRef]

4. Liu, Z.; Mao, W.; Wang, W.; Zheng, Z. Preparation of semi-solid A380 aluminum alloy slurry by serpentine channel. Trans. Nonferrous Met. Soc. China 2015, 25, 1419-1426. [CrossRef]

5. Alvani, S.M.J.; Aashuri, H.; Kokabi, A.; Beygi, R. Semisolid joining of aluminum A356 alloy by partial remelting and mechanical stirring. Trans. Nonferrous Met. Soc. China 2010, 20, 1792-1798. [CrossRef]

6. Liu, Z.; Mao, W.; Liu, X. Characterization on morphology evolution of primary phase in semisolid A356 under slightly electromagnetic stirring. Trans. Nonferrous Met. Soc. China 2010, 20, s805-s810. [CrossRef]

7. Wannasin, J.; Martinez, R.A.; Flemings, M.C. Grain refinement of an aluminum alloy by introducing gas bubbles during solidification. Scr. Mater. 2006, 55, 115-118. [CrossRef]

8. Lü, S.; Wu, S.; Dai, W.; Lin, C.; An, P. The indirect ultrasonic vibration process for rheo-squeeze casting of A356 aluminum alloy. J. Mater. Process. Technol. 2012, 212, 1281-1287. [CrossRef]

9. Hong, C.P.; Kim, J.M. Development of an advanced rheocasting process and its applications. Solid State Phenom. 2006, 116-117, 44-53. [CrossRef]

10. Taghavi, F.; Ghassemi, A. Study on the effects of the length and angle of inclined plate on the thixotropic microstructure of A356 aluminum alloy. Mater. Des. 2009, 30, 1762-1767. [CrossRef]

11. Kund, N.K. Influence of plate length and plate cooling rate on solidification and microstructure of A356 alloy produced by oblique plate. Trans. Nonferrous Met. Soc. China 2015, 25, 61-71. [CrossRef]

12. Khosravi, H.; Eslami-Farsani, R.; Askari-Paykani, M. Modeling and optimization of cooling slope process parameters for semi-solid casting of A356 Al alloy. Trans. Nonferrous Met. Soc. China 2014, 24, 961-968. [CrossRef]

13. Jeong, C.Y. Effect of alloying elements on high temperature mechanical properties for piston alloy. Mater. Trans. 2012, 53, 234-239. [CrossRef]

14. Qi, M.; Kang, Y.; Xu, Y.; Wulabieke, Z.; Li, J. A novel rheological high pressure die-casting process for preparing large thin-walled Al-Si-Fe-Mg-Sr alloy with high heat conductivity, high plasticity and medium strength. Mater. Sci. Eng. A 2020, 776, 139040. [CrossRef]

15. Chen, Y.; Hu, Q.; Pan, S.; Zhang, H.; Liu, H.; Zhu, B.; Liu, X.; Liu, W. Influences of Cu content on the microstructure and strengthening mechanisms of Al-Mg-Si-xCu alloys. Metals 2019, 9, 524. [CrossRef]

16. Gan, J.; Huang, Y.; Wen, C.; Du, J. Effect of Sr modification on microstructure and thermal conductivity of hypoeutectic Al-Si alloys. Trans. Nonferrous Met. Soc. China 2020, 30, 2879-2890. [CrossRef]

17. Fracchia, E.; Gobber, F.S.; Rosso, M. Effect of alloying elements on the Sr modification of Al-Si cast alloys. Metals 2021, 11, 342. [CrossRef]

18. Sweet, L.; Zhu, S.M.; Gao, S.X.; Taylor, J.A.; Easton, M.A. The effect of iron content on the iron-containing intermetallic phases in a cast 6060 aluminum alloy. Metall. Mater. Trans. A 2011, 42, 1737-1749. [CrossRef]

19. Ye, H. An overview of the development of Al-Si-alloy based material for engine applications. J. Mater. Eng. Perform. 2003, 12, 288-297. [CrossRef]

20. Zhang, F.; Zhang, C.; Liang, S.M.; Lv, D.C.; Chen, S.L.; Cao, W.S. Simulation of the composition and cooling rate effects on the solidification path of casting aluminum alloys. J. Phase Equilib. Diffus. 2020, 41, 793-803. [CrossRef]

21. Ravi, M.; Pillai, U.T.S.; Pai, B.C.; Damodaran, A.D.; Dwarakadasa, E.S. A study of the influence of mischmetal additions to Al-7Si-0.3Mg (LM 25/356) alloy. Metall. Mater. Trans. A 1996, 27, 1283-1292. [CrossRef]

22. Lu, S.Z.; Hellawell, A. Modification of Al-Si alloys: Microstructure, thermal analysis, and mechanisms. JOM 1995, 47, 38-40. [CrossRef]

23. Li, J.H.; Albu, M.; Hofer, F.; Schumacher, P. Solute adsorption and entrapment during eutectic Si growth in Al-Si-based alloys. Acta Mater. 2015, 83, 187-202. [CrossRef]

24. Mazahery, A.; Shabani, M.O. Modification mechanism and microstructural characteristics of eutectic Si in casting Al-Si alloys: A review on experimental and numerical studies. JOM 2014, 66, 726-738. [CrossRef] 
25. Žbontar, M.; Petrič, M.; Mrvar, P. The influence of cooling rate on microstructure and mechanical properties of AlSi9Cu3. Metals 2021, 11, 186. [CrossRef]

26. Wisutmethangoon, S.; Thongjan, S.; Mahathaninwong, N.; Plookphol, T.; Wannasin, J. Precipitation hardening of A356 Al alloy produced by gas induced semi-solid process. Mater. Sci. Eng. A 2012, 532, 610-615. [CrossRef]

27. Elahi, M.A.; Shabestari, S.G. Effect of various melt and heat treatment conditions on impact toughness of A356 aluminum alloy. Trans. Nonferrous Met. Soc. China 2016, 26, 956-965. [CrossRef]

28. Wang, Q.G. Microstructural effects on the tensile and fracture behavior of aluminum casting alloys A356/357. Metall. Mater. Trans. A 2003, 34, 2887-2899. [CrossRef]

29. Riestra, M.; Ghassemali, E.; Bogdanoff, T.; Seifeddine, S. Interactive effects of grain refinement, eutectic modification and solidification rate on tensile properties of Al-10Si alloy. Mater. Sci. Eng. A 2017, 703, 270-279. [CrossRef]

30. Guo, J.; Guan, Z.P.; Yan, R.F.; Ma, P.K.; Wang, M.H.; Zhao, P.; Wang, J.G. Effect of modification with different contents of Sb and Sr on the thermal conductivity of hypoeutectic Al-Si alloy. Metals 2020, 10, 1637. [CrossRef]

31. Liu, Z.; Mao, W.; Wan, T.; Cui, G.; Wang, W. Study on semi-solid A380 aluminum alloy slurry prepared by water-cooling serpentine channel and its rheo-diecasting. Met. Mater. Int. 2020, 2, 672-683. [CrossRef]

32. El-Mahallawi, I.S.E.; Mahmoud, T.S.; Gaafer, A.M.; Mahmoud, F.H. Effect of pouring temperature and water cooling on the thixotropic semi-solid microstructure of A319 aluminium cast alloy. Mater. Res. 2015, 18, 170-176. [CrossRef]

33. Zhu, W.; Mao, W.; Tu, Q. Preparation of semi-solid 7075 aluminum alloy slurry by serpentine pouring channel. Trans. Nonferrous Met. Soc. China 2014, 24, 954-960. [CrossRef]

34. Guan, R.G.; Cao, F.R.; Chen, L.Q.; Li, J.P.; Wang, C. Dynamical solidification behaviors and microstructural evolution during vibrating wavelike sloping plate process. J. Mater. Process. Technol. 2009, 209, 2592-2601. [CrossRef]

35. Liu, W.; Tan, J.; Li, J.; Ding, X. Influence of process parameters by vibrational cooling-shearing slope on microstructures of semi-solid ZAlSi9Mg alloy. Adv. Mater. Res. 2011, 211, 142-146. [CrossRef] 